\title{
Seleukos Krallığı'nda İsyan ve İhanet Çemberi: Akhaios İsyanı ve Sardeis Kuşatması
}

\author{
Revolt and Treachery in Seleucid Kingdom: Achaeus's Revolt and Sardis Siege
}

Elif ALTEN GÜLER *

Öz: Büyük İskender’in ölümünün ardından Makedon Krallığı, ardıllarının arasında paylaştırılmış ve daha sonra birbirleri arasında çıkan mücadeleler sonucu üç büyük krallık (Mısır, Küçük Asya, Makedonya) ayakta kalabilmiştir. Bu krallıklar arasından Seleukos Krallığg'nda yaşanan en parlak dönem ise III. Antiokhos (MÖ 223-187) zamanına tekabül etmektedir. Krallık her ne kadar ihtişamlı görülse de Antiokhos'un başa geçtiği ilk zamanlarda iç isyanlarla karşılaşması (Media-Persis Ayaklanmaları) yeni başa geçen kralı zorlamıştır. Bu sırada komutanı Akhaios'un I. Attalos üzerine ilerleyip Küçük Asya hakimiyetini ele geçirmiş ve Sardis'i krali başkent yaparak Mysia'ya ilerlemiştir. Komutanın Lykaonia, Phrygia, Lydia, Karia'nın doğusu ve merkezi gibi doğu bölgelerinde Seleukos otoritesinin de kurduğunun kanıtı ise, kendi adına krali gümüş sikkeler basmasıdır. Bunların ardından gerek dış etkiler gerekse zamanla oluşan iç çekişmeler ve hırslar dolayısıyla başlangıçta hiç düşünmediği hatta III. Seleukos’un katillerini yakalatıp cezalandırmış ve atandığı yerleri de iyi bir şekilde yöneterek Küçük Asya’daki kontrolü sağlamasına yardım etmiştir. Öz yeğeni III. Antiokhos'a karşı ayaklanmıştır. III. Antiokhos ise Pergamon kralı I. Attalos'u müttefik olarak yanına alıp Akhaios'a karşı mücadeleye başlamış ve Seleukos komutanının ele geçirdiği yerleri teker teker ele geçirip krallığına katmıştır. Sonunda Akhiaos'u Sardis’te kıstıran III. Antiokhos iki yıllık kuşatmanın ardından amcasını ancak bir ihanet sonucu ele geçirmiş ve acımasız bir şekilde cezalandırmıştır.

Anahtar sözcükler: III. Antiokhos, Akhaios, Sardis Kuşatması, İsyan, İhanet

Abstract: After the death of Alexander the Great, the Kingdom of Macedon was divided among his successors, and the struggles between them later resulted as the creation of three great kingdoms: Egypt, Asia Minor, and Macedonia. The most brilliant period for the Seleucid kingdom was the era of Antiochus III between 223 and 187 B.C. III. Although magnificent, the kingdom was forced to confront internal revolts in the early days of Antiochus (such as the revolt of Media-Persis), Achaeus caused Attalus I to conquer Asia Minor, make Sardis his royal capital and proceeded to Mysia. His royal silver emission is also a sign of the establishment of Seleucid authority in the eastern regions of Lycaonia, Phrygia, Lydia, eastern and central Caria. Moreover, Achaeus, the Seleucid commander, felt a powerful desire to attain control over the external effects, the kingdoms and attain his ambitions. Firstly, he didn't think about them, and helped to capture murderers of Seleucus III and to punish them. Achaeus managed the districts he inducted as a commander and helped Antiochus to control Asia Minor. Then this power caused him to want to rule the kingdoms and he rebelled. Antiochus uniting his forces with Attalus I, king of Pergamon, began to struggle against Achaeus, taking the places seized from the Seleucid commander one by one and added them to his kingdom. He squeezed Achaeus, his nephew, into Sardis after the 2-year siege and captured his uncle as a result of betrayal and killed unmercifully.

Keywords: Antiochus III the Great, General Achaeus, Siege of Sardis, Revolt, Treachery

\footnotetext{
* Arş. Gör., Akdeniz Üniversitesi, Edebiyat Fakültesi, Tarih Bölümü, Antalya. elifalten@akdeniz.edu.tr, https://orcid.org/0000-0001-7666-7141
} 


\section{Giriş}

Büyük İskender'in ölümünün ardından krallık için yönetime geçecek herhangi bir varis kalmadığından diodokhoi olarak adlandırılan Makedon Krallığı'ndaki komutanlar arasında bir dizi çarpışmalar vuku bulmuştur. MÖ 323'ten itibaren başlayan bu karışıklık, MÖ. 281 yılındaki Hermos-Gediz Irmağı yakınındaki Kurupedion Muharebesi’nde I. Seleukos'un da ölmesiyle üç büyük krallık kalmıştır: Bunlar, Ptolemaios II Philadelphos (MÖ. 282-242) yönetiminde Mısır; Antiokhos I Soter'de (MÖ 281-261) Küçük Asya; Antigonos II Gonatas hakimiyetinde ise (MÖ. 279-239) Makedonya'dır. Üç krallığın topraklarının sınırlarının belirlenmesi üzerine Seleukos Krallığı'nın güçlenmeye başlaması ile bu kez II. Ptolemaios Philadelphos ve I. Antiokhos (MÖ 281-261) üzerine ilerleyerek iki büyük güç yerini MÖ 276 y1lında baş gösteren Suriye Savaşları'na bırakmıştır. Birinci Suriye Savaşı'nda (MÖ 272-262) aralarında yaşanan ilk çatışmadan II. Ptolemaios zafer kazanarak Ionia, Karia, Lykia, Pamphylia ve Kilikia sahillerini egemenliğine katmıştır. I. Antiokhos'un ölümü ile başa geçen Antiokhos II Theos/Teoeides (MÖ 261246) Seleukosların kaybettikleri egemenlikleri yeniden sağlamaya çalışması üzerine II. Ptolemaios tekrar Seleukos Krallığı'na savaş açmıştır (MÖ 260-253). II. Antiokhos savaş sonucunda Miletos, Samos ve Ephseos gibi ada ve kent devletlerini özgürleştirmiştir. Ptolemaios Krallığı'nın zayıflatmaya çalıştığı Seleukoslar tekrar eski gücüne ve egemenlik alanına sahip olmuştur. Seleukos kralı, Ptolemaioslarla yapılan barış anlaşmasını eşi Laodike'den boşanıp II. Ptolemaios'un kızı ile evlenerek perçinlemiştir. Laodike ise daha sonra Berenike'den olan çocuğun varis olmaması için II. Antiokhos'u zehirlemiştir ve ölümünden önce ise II. Seleukos Kallinikos’u (MÖ 246-227) varis olarak atamıştır. Berenike ise oğlunu varis yapmak üzere II. Ptolemaios yerine geçen Ptolemaios III Euergetes'i yardıma çağırsa da Mısır kralı yardıma gidene kadar Berenike ve oğlunun ölüm haberini almıştır. III. Ptolemaios ise bu intikamı almak için Üçüncü Suriye Savaşı’nı (MÖ 246-41) başlatacak taarruza geçmiştir. Mısır'daki iç karışıklıklar dolayısıyla ülkesine dönse de II. Seleukos bazı saldırılar düzenlemiş, ama bunlardan da yenik ayrılarak iki krallık arasında 10 yıllık barış anlaşması yapılmıştır. Polybios'a göre (V. 58. 10) Selukoslar bu savaşı kaybederek Seleukeia Pieria'y1 (Samandağ) elden çıkarmış ve bu zamana kadar ele geçirdikleri çoğu yeri bu dönemde kaybetmesi Seleukos Krallığı için bir gerileyiş sinyali olarak da algılanmıştır.

II. Selukos doğuyu, Antiokhos Hieraks ise Torosların batısını yönetirken Antiokhos Hieraks annesinin desteği ile kardeşine savaş açmış (Kardeşler Savaşı, MÖ 240-237) ve II. Seleukos’u yenmiştir. MÖ 236'da barış yapılmış, ardından da Antiokhos Hieraks, I. Attalos üzerine yürümüş ancak kral yenilmiş ve kaçarken kendi müttefileri olan Galatlar tarafindan öldürülmüştür (Phylarkh. fr. 49; Euseb. chron. I. 253; Pomp. Trog. prolog. 27=Iust. XXVII. 3. 9; Ael. Anim. VI. 44; Solin. de mir. mundi 45; Plin. Nat. VIII. 158).

Aynı yıl Seleukos II Kallinikos ‘Pogon’un da aniden ömesi üzerine yerine oğlu III. Seleukos başa geçmiş ve kendisi Küçük Asya ile ilgilenme sürecinde III. Antiokhos'u doğuya yollamıştır (Polyb. II. 71. 4; Porphyr. Adver. Khr. 46; Euseb. Chron. I. 40. 12). Küçük Asya'nın batısında önceden kaybedilen yerleri geri alma ve otorite boşluğunu ortadan kaldırma çabasına giren III.

Seleukos, komutanları Andromakhos ve Akhaios'u Attalos I Soter üzerine göndermiştir. Fakat Andromakhos, III. Ptolemaios'un birliklerine esir düşmüştür (Polyb. IV. 51. 1; OGIS 277; Austin 1981, 197; Grainger 2010, 181). İki kez Attalos'a karş1 yenik duruma düşen III. Seleukos ise MÖ. 223'te ordusunun başına geçip yanına yetenekli bir komutan olan kardeşi Akhaios'u da alarak Torosları aşmış ve Phrygia'ya doğru ilerlemiştir (Polyb. IV. 48. 6-7. Ayrıca bk. Meadows 2009, 70; Alten 2015, 29). Ancak yolda sebebini bilmediğimiz bir nedenden ötürü Galat asıllı subayları Apaturios ve Nikanor tarafindan öldürülmüştür (Polyb. IV. 48. 7-8; V. 40. 5-6; 41. 2; 
App. Syr. 66; Iust. XXVIII; XXIX. 1. 3; Euseb. chron. 253b-263a; Porphyr. Adver. Khr. 44. Ayrica bk. BabylChron_Brit. Mus. 35603. R2-3; Polyb. II. 71. 4; IV. 2. 7; 48. 6-8; XXIX. 8. 56; Pomp. Trog. Prolog. 27; Hieron. Chron. 139. 2 [1794]; Sulpit. II. 19 a; Malal. Chron. 205; Euseb. Exc. Barb. 46A; Konu hakkında daha detaylı bilgi için bk. Magie 1950, 739 dn. 25; Mitchell 1993, 42 dn. 2; Arslan 2000, 84 dn. 305; 2010, 261 dn. 1014). Akhaios derhal kralın kardeşi olarak iki katili yakalatıp astırmıştır. Kısa süre içinde birlikler arasındaki karışıklılıkları bastırarak ordunun komutasını üstlenmiştir.

\section{Antiokhos'un Başa Geçişi ve İç karışıklıklar}

MÖ 223’te Seleukos III Keraunos Soter öldürünce babasının yerine Seleukos tahtına doğu eyaletlerinde görev yapan oğlu III. Antiokhos (Euseb. Chron. I. 253; Kutsal Kitap, Eski Antlaşma, Dan. XI. 10) geçmiştir. III. Antiokhos yaşının küçüklüğünden olsa gerek tecrübeli bürokrat Karialı Hermeias'1 kral naibi konumuna getirmiştir. Ardından da onun tavsiyesi ve teşvikiyle Küçük Asya yönetimini ve Toros'un batısının güvenliğini sağlamak için amcası Akhaios'u (Polyain. Strat. IV. 17; Polyb. IV. 48. 9-10; ayrica bk. Austin 1981, 146; Schmitt 1964, 109-11, Ma 1999, 55. Komutan olarak atanması için bk. Polyb. IV. 2. 6; 48. 3; VIII. 20. 11) atamıştır. Ardından Suriye'nin doğusunda yer alan Media'ya yönetmesi için vali olarak Molon'u, Persis'e ise Molon'un kardeşi Aleksandros'u görevlendirmiştir. Zamanla III. Antiokhos'un yaşının küçük ve tecrübesiz olduğunu düşünen zira o sıralarda 20'li yaşlardaydı, Molon ve kardeşi Aleksandros Seleukos tahtındaki otorite boşluğundan faydalanmak isteyerek Antiokhos'a karşı isyan etmişlerdir (Polyb. V. 41. 1-42. 9). Bunun üzerine III. Antiokhos, Media ve Persis ayaklanmalarını bastırmak üzere komutanları Ksenon ve Theodotos (Hemiolios) yönetiminde doğuya bir ordu göndermiştir. Bu sırada amcası Akhiaos ise, MÖ 222/221 y1lında Küçük Asya’ya doğru ilerleyerek I Attalos üzerine yürümüştür (Polyb. IV. 48. 11-12; Cardinali 1968, 46-47). Akhaios kısa süre içinde beklenmedik bir şekilde I. Attalos’u bozguna uğratmış ve tek bir zaferle Attalos Krallığı'nın Pergamon hariç onun sahip olduğu tüm Batı Asya topraklarını ele geçirmiştir (Polyb. IV. 48. 11). Böylelikle Teos, Kolophon, Kyme, Myrina, Phokaia, Aigai, Temnos ve Troas ile sınır olan kentlerle Mysia'nın bir bölümü Seleukos'lar hakimiyetine katmıştır (Ma 1999, 55; Sartre 2003, 43-4). Ardından Sardeis kentini krali başkenti ilan etmiş ve adına krali sikkeler bastırmıştır (SC I, n ${ }^{0}$ 952; Mørkholm 1969, 15; Newell 1977, $n^{0}$ 1439).

Bu sırada III. Antiokhos, Ptolemaios III Euergetes'in hastalanarak kısa süre içinde öldüğü haberini alınca yerine geçen Ptolemaios IV Philopator'un (MÖ 221-204) başa geçmesinden cesaret alarak Mısır üzerine yürümüştür (Polyb. II. 71. 3). Ancak Media ve Persis ayaklanmaları için görevlendirdiği komutanların ayaklanmayı bastırmakta yetersiz kaldıklarını anlayınca Dördüncü Suriye Savaşı'nı (Raphia Savaşı) yarım bırakıp, iç isyanları bastırmak için dönmek zorunda kalmıştır. Kısa süre içinde de Molon ve kardeşlerinin çıkardığı isyanları şiddetli bir şekilde bastırarak onları ölümle cezalandırmıştır (Polyb. V. 54. 6 -7; ayrıca bk. Taylor 2013, 3334). Ardından yarım bıraktığı Dördüncü Suriye Savaşı için Ptolemaioslar üzerine ilerlemiştir. Önce krallar arasında karşılıklı mektulaşmalar olmuş, ancak sorun her iki taraf açısından da çözülmez bir hal aldığında aralarındaki problemleri kılıçla çözme yoluna gitmişlerdir (Polyb. V. 1. 5; Tcherikover 1959, 52-5; Austin 1981, 148). Yapılan muharebe sonucunda Seleukoslar yenilmiş ve barış anlaşması imzalanmıştır (Porphyr. Adver. Khr. 44. Pomp. Trog. prolog. $30=$ Iust. XXX. 1. 7). 


\section{Akhaios İsyanı (MÖ 219-213)}

III. Antiokhos Dördüncü Suriye Savaşı için Ptolemaioslar üzerine ilerlerken, amcası Akhaios I.Attalos'u ağır bir yenilgiye uğratarak Pergamon hariç tüm Batı Anadolu'yu ele geçirmişti. Ancak Akhaios'un bu kadar kısa süre içinde böylesi güçlenmesi kral naibi Hermeias'ın da hoşuna gitmemiş görünür. Daha önce Media ve Persis ayaklanmaları konusunda toplanan konseyde III. Antiokhos'un ne yapılmasına dair fikir sorduğunda Epigenes, kralın bizzat isyanları bastırmak için ilerlemesi gerektiğini söylediğinde, Hermeias bunun gizli bir planın parçası olabileceğini ve bu durumda kral ve yanındakileri savunmasız bırakabileceğini söyleyerek kralı uyarmıştır. Durumu öyle ustalıkla idare etmiştir ki, kral ile konsey önünde küçük düşürülen Epigenes üzerinde şüphe tohumları ekmiştir (Poly. V. 42. 1-3; ayrıca Austin 1981, 147). Şimdi de kral üzerindeki otoritesini ve güvenini kullanarak aynı taktiği Akhaios üzerinden uygulamaya çalışmış ve sözde Misır kralı IV. Ptolemaios’tan Akhaios’a elçi gönderilerek Seleukos Krallığı'nı ele geçirmesi için kendisine maddi-manevi yardım edeceğine dair sahte mektup düzenlemiştir. Böylelikle III. Antiokhos'u hem amcası Akhaios'a karşı hem de Mısır Krallığı'na karşı kışkırtmıştır.

Antiokhos bu duruma inanmış olsa gerektir. Amca ile yeğen arasında geçen mektuplaşmalar ve elçilerin görüşmelerinden bir sonuç alınamamış olsa gerektir ki Akhaios kısa süre içinde III. Antiokhos'a karşı isyan etmiş̧tir. Anlaşıldığı üzere Akhaios'un III. Antiokhos'a karşı krallığının ilk yıllarında ayaklanma gibi bir niyeti olmasa gerekti. Zira olsaydı kardeşi Seleukos Kralı Seleukos III Keraunos Soter'in (MÖ 225-223) katillerini cezalandırdıktan sonra kendisine ordu tarafından teklif edilen kralık tacını alır ve o zaman yeğenine karşı ayaklanırdı (Polyb. IV. 48. 9-10, ayrica bk Alten 2015, 44). Ayrıca III. Antiokhos Molon ve kardeşlerinin isyanları ve Dördüncü Suriye Savaşı'yla ilgilenirken de elinde ayaklanma imkanı olmasına karşı herhangi bir hamlede bulunmadığı görünür. Bu durumu, Pergamon kralı I. Attalos'a karşı ilerleyip onu sindirmesi (Polyb. IV. 48. 11) ve kısa süre içinde Küçük Asya'da büyük bir güç elde etmesi değiştirmez. Ancak zaman içinde her iki tarafında da giderek güç kazanması ve yakın çevresindeki danışmanlarının görüşleri amca ile yeğenin arasını açmış görünür. Ancak III. Antiokhos'ta da Akhaios'un kısa süre içinde Küçük Asya'da büyük bir güç elde etmesinin yarattığı tedirginliğin görünmeden var olan etkisi de sezilebilmektedir. Polybios’a (loc. cit.) göre bu şüpheyi iftiraya/ihanete varacak dereceye körükleyen sahte belge düzenlemekten dahi çekinmeyen kral naibi Hermeias'ın rolu büyüktür.

Diğer taraftan Akhaios'un da zamanla güç zehirlenmesine tutulduğu ve artık krallığın paylaşılamaz olduğunu ve gücü kendi elinde toplama arzusuyla kendisini kral ilan etmeyi düşünerek girişmiş olabileceği de ihtimal dahilindedir. Sonuç itibarıyla isyanın gerçek nedeni tam olarak bilinemekle birlikte elimizde Polybios'un naratizasyonu çevresinde aktarılan bilgiler mevcuttur. Historiografa (IV. 48) göre III. Seleukos öldüğünde kendisine askerler tarafindan krallık bahşedildiğinde bunu kabul etmeyen vali, artık gücünün zirvesinde olması ve Batı Anadolu ile güney kıyılarındaki çoğu kenti sindirmesi sayesinde MÖ 219 yılında Seleukoslara karşı kendi krallığını ilan etmiştir. Antiokhos'un o sıralar genç olması, Akhaios'un istediği güce ulaşması (kentleri ele geçirerek yaptığı müttefiklik anlaşmaları için bk I.Delphinion 143; I.Tralleis 20; 26) ve kendine güveninin artması sonucu iç isyanlarla birlikte mevcut olan otorite boşluğunu kullanarak ayaklanma gerçekleştirdiği düşünülebilir (Mcdonald 1903, 107; Leuze 1923, 188). Bu sırada durumu öğrenen III. Antiokhos, Ptolemaioslarla mücadele ederken önce Akhaios'a elçileri vasitasıyla bir ultimatom göndermiş (Polyb. V. 57. 1-2), fakat bu durum amcayı kararından döndürmeye yeterli olmamıştır. Bunun üzerine III. Antiokhos’un Suriye'yi bırakıp Ptolemaioslar ile mücadele için bölgeden ayrılması Akhaios'un askerlerini toplayıp 
Suriye’ye doğru ilerlemesini meşrulaştırmıştır (Polyb. V. 57. 3-4; ayrıca bk. Bell 2007, 58).

Ani bir kararla Küçük Asya'daki başarılarından cesaret alan Akhaios ise, bu sırada güneye yönelmek istemiştir. Ancak Phrygia üzerinden Suriye’ye doğru ilerlerken Lykaonia sınırında halen kendi askerleri arasında gerçek kralları olan III. Antiokhos'la çarpışmak istemeyen askerlerinin çıkarttığı ayaklanma Akhaios'un bu kararını tekrar gözden geçirmesine sebep olmuştur. Bu şekilde önce askerlerini sakinleştirmiş daha sonra da rotasını Pisidia'ya çevirmiştir (Polyb. V. 57. 6; ayrıca bk. Ma 1999, 56; Leake 1824, 44-45).

Akhaios ayaklanma sırasında mümkün olduğunca Ptolemaioslar ve Antigonos'larla mücadeleye girmemiş, hedef olarak I. Attalos'u kıskaca almıştır (Polyb. IV. 48. 2). Komutanı Garsyeris ile birlikte Anadolu'nun iç ve batı kıyıları dahil olmak üzere çoğu yeri ele geçirmiştir (Polyb. V. 77. 1; ayrıca bk. Meadows 2009, 73). Milyas ve Pamphylia kentlerinin çoğunu kendi himayesine almış ve Milyas'ta bulunan Komama, Olbasa, Pogla (Ma 1999, 58) gibi küçük kentlerin yanı sıra Termessos (Güllük Dağı) ve Sagalassos (Ağlasun) da Akhaios'un tarafina geçmiştir (Schmitt 1964, 262). Bu sırada Akhaios, I. Attalos üzerine yürümek için ilerlerken III. Antiokhos, müttefik olarak I. Attalos'u yanına çekmeye karar vermiştir. Akhaios'un Pergamon Krallı̆̆ı'nın üzerine ilerleyerek sindirmeye çalışması I. Attalos'un kendi krallığını koruması adına bir çıkar durumu teşkil etmiştir. Seleukos kralı, I. Attalos kendisine yardım ettiği takdirde Pergamon krallığının sınırlarını tanımaya söz vermiştir (Polyb. V. 107. 4; ayrıca bk. Ma 1999, 60; Arslan 2000, 88; Bell 2007, 59). Attalos I Soter ve Antiokhos III Megas arasındaki anlaşma, ise şuan Manisa Müzesi'nde muhafaza edilen bir yazıtta kanıtlanmıştır (Malay 1987, 7-17; SEG XXVII. 1010; Ma 1999, 19; 288-292).
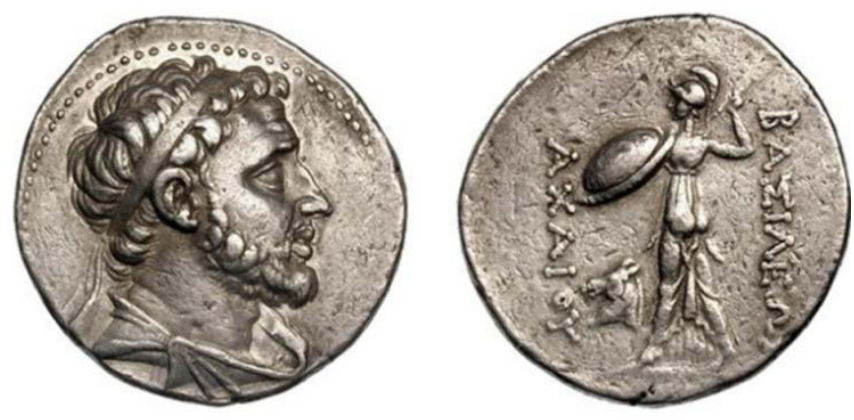

Fig. 1. Akhaios Sikkesi: Kaynak: www.wildwinds.com

\section{Kuşatma ve İsyanın Bastırılması (MÖ 215-213)}

Akhaios'un (MÖ 219-213) altı yıl boyunca kentlerle yoğun ilişkisi ve bağlantıları ile ilgili yazışmalarla ilgili herhangi bir veri bulunmasa da bu döneme ait belgeler de oldukça azdır. Antiokhos ilk kez Asia Minor'a ilerleyerek hem Akhaios'un egemenlik kurduğu yerleri fethederek ilerlemiş hem de kentleri iyileştirme politikası izlemiştir. III. Antiokhos krallığını geniş sınırlara ulaştırmak için Suriye Savaşı'ndan önce arkada düşman ve sorun bırakmadan ilerlemek istemesi iç isyanlarının sonuncusu ve en çetini olan Akhaios'a karşı ilerlemekti. Pergamon krallığı ile de uzun yıllar savaşması ve krallığın en büyük düşmanlarından biri olmasına rağmen Attalos I Soter ile ittifak içerisine girmesi Seleukos kralının bu isyanı kısa sürede çözüme kavuşması için uğraştığının göstergesidir. MÖ 215'te Pergamon kralı ile III. Antiokhos güçlerini birleştirerek komutanın üzerine ilerlemeye başlayınca onlarla başa çıkamayacağını anlayan Akhaios krali başkenti Sardis'e çekilmek zorunda kalmıştır (Gauthier 1989, 15-19; Ma 1999, 61). Sardes civarındaki kuşatmada çatışmalar ve savaş çok hızlı bir şekilde ilerlerken askerler birbirlerine karşı her türlü tuzak ve karşı saldırıyı deneyip yüz yüze 
mücadele etmişlerdir. Kuşatma bir yıldan fazla sürünce III. Antiokhos'un komutanı olan Giritli Lagoras da kuşatmaya müdahil olmuştur. Askeri tecrübe bakımından diğerlerini geride bırakacak kadar yetenekli olan Lagoras, en güçlü kentlerin aslında savunma hatlarına güvenerek gelen saldırıları önemsememesi sonucu bu kentlerin düşman tarafından kolayca ele geçirildiğini görmüş, ancak Akhaios tarafindan iyi bir şekilde savunulan Sardis'in tecrübelerine göre kolay kolay ele geçirilemeyeceğini düşünmüştür. Çünkü kent o zamana kadar kuşatılmak kaydıyla sadece bir defa, o da Kyros tarafindan ele geçirilmişti (Hdt. I. 84).

Antiokhos ve komutanları Sardis'in doğa ve insanlar tarafından son derece iyi bir şekilde tahkim edilmiş olduğunu ve askerlerden her biri aynı anda kentin her tarafından ani hücum yapsa bile kentin düşmesinin çok zor olduğunu fark etmişlerdir. Bu yüzden öncelikle bir yıldan uzun süredir dayanan kentin iaşe hattını keserek teslim olmaya zorlama planı yapmıştır. Her fırsatı kollayıp olasılıkları araştırarak tüm dikkatlerini kent ile kale arasındaki iaşe hattını kesmeye vermişlerdir. Antik kaynaklar bundan hemen sonra cereyan eden olaylar konusunda sesiz de olsalar Antiokhos'un ordusu bu taktikde bir dereceye kadar bir dereceye kadar başarılı oldukları varsayılabilir. Zira bir süre sonra kentin testere (= prion [ $\pi \rho i ́ \omega v])$ denilen dik yerinden ölü bedenlerin, atların iç organlarının, ölmüş katırların cesetleri atıldıktan sonra buraya çok sayıda kuş ve akbabanın gökyüzünde daireler çizerek toplanışını izlemişlerdir. Ardından karınlarını tıka basa doyuran bu kuşların dinlenmek için tepenin zirvelerini koruyan tahkimli sur duvarlarının üstüne tünediklerini görmüşlerdir. Bu şekilde kentin bu tarafındaki duvarların savunmasız ve terkedilmiş olduğunu anlamışlardır. Bu yüzden Lagoras aynı şekilde yaklaşık iki asır ve çeyrek yüzyıl önce Kyros'un ordusundaki birliklerin yaptığı gibi geceleyin gizlice buraya tırmanıp surlara merdiven dayayarak duvara tırmanabileceğini ve kente beklenmedik bir şekilde sızabileceğini düşünmüştür. Tepenin belli bir noktasında bunu yapmanın mümkün olduğunu anlaması üzerine durumu III. Antiokhos'a bildirmiştir (Polyb. VII. 15. 8-11). III. Antiokhos ise ona planını uygulamasını rica etmiş; Lagoras ise hem fikir konusunda yetenekli hem de cesaret bakımından diğerlerinden üstün olduğunu belirttiği hypaspistes’lerin (kalkan taşıyan hafif silahlı asker) komutanı Dionysios ile Aitolialı Theodotos'u yanında istemiştir (Polyb. VII. 16. 2-3). III. Antiokhos komutanın istedikleri kişileri de yanına vermiş ve üç komutan da detayları görüşmüşlerdir. Ayın olmadığı geceyi bekleyerek on beş adam seçmişlerdir. $\mathrm{Bu}$ adamların yapacakları şey, merdivenleri taşıyıp onlarla birlikte duvarı tırmanmak ve tehlikeli girişimde onlarla birlikte yer almaktı. Otuz kişilik bir diğer grubun görevi ise pusuda bekleyip diğer grubun gizlice kalenin içinden ilerleyerek kapıyı açmasını beklemekti. Bu otuz kişilik grup da kale kapısından geçip geçiş kapılarının saldırı durumuna göre menteşe ve kol kısımlarını kesecekti. Kale kapılarının açılmasıyla ilerlemek için bekleyen ve içeri girince yukarı kentteki tiyatro ile ilgilenecek olan 2000 kişilik grup da kale ve kentteki garnizonlarla ilgilenmek üzere uygun mevzilerde konuşlandırılmıştı. Söz konusu planın Akhaios'un birliklerinde baş gösteren açlık ve surlardaki mevzilerini savunmayı bırakan bir dizi askerin görevlerini ihmal etmesi sonucu başarıyla işlemiş görünür. Öyle ki, Antiokhos’un ordusundaki askerlerin aynı zamanda ve uyumlu çalışması sonucu kayalıkların da kenar çıkıntısı dolayısıyla tırmanırken kendilerini gizlemesi sayesinde dış kent surları aşılmıştır. Polybios'a (VII. 18. 1-10) göre, Lagoras, Theodotos ve Dionysios surları aştıktan sonra birliklerin bazıları karşılaştıkları düşmanla ilgilenirken bazıları kapıların kol demirlerini kesmekle görevlendirilmiştir. Kapılara aynı anda yüklenmişler ve çok geçmeden de kapıları açmışlardır. 2000 asker buradan kente girerek tiyatronun yukarısı ile uğraşmış; diğer birlikler de hem duvarlardan hem de Pers kapılarından kente saldırmışlardır. Bu sırada kent komutanı Aribazos kente giren düşmanlara karşı koymaya çalışmıştır. Bu yer ele geçtikten sonra düşman birlikleri geri çekilmiş ve kapılara hakim olan kralın birlikleri geri çekilen düşman birliğine daha da çok yaklaşmışlardır. Kent 
yağmalanmaya başlanmış ve diğer çevre kapılar da açılarak kent istila edilmiştir. Aribazos ve birliği istilacılarla kısa bir çarpışmadan sonra kaleye aceleyle gitmiştir. Theodotos ve Lagoras tiyatronun çevresinde kalarak tüm kuşatma boyunca yardımcı birlik olarak kalmış, ordunun geri kalanı ise her yerden sel gibi akarak kenti almışlardır. Böylelikle kral birliklerinden bazıları karşılaştıkları düşmanları katlederken diğerleri aşağı kentteki evleri ateşe vermiş, kent talan edilerek yağmalanmıştır. Sardis tamamen tahrip edilerek düşmüş ve baskına uğrayan Akhaios kentin komutanı ile birlikte elinde kalan birliklerle kentin iç kalesine çekilmek zorunda kalmıştır.

Kent, doğal ve insan eliyle yapılmış sağlam savunma sistemine sahip olduğundan, buraya yapılan birkaç başarısız denemenin ardından bu kuşatmanın aşağı kentten daha zor olacağ anlaşılmıştır. Bu sırada Misır kralı IV Ptolemiaos'un komutanlarından Sosibios, Akhaios’u kurtarmak için planlar yapmıştır. Sosibios, Ptolemaios Sarayı'nda uzun süre yüksek mevkilerde bulunan, akıl olarak üstün, cesaret bakımından olağanüstü ve askeri strateji konusunda da bir o kadar yetenekli bir kişi olan Giritli Bolis (Ptolemaios tarafında iken çıkar çatışması sonucu Seleukos tarafina geçmiştir bk. Ehling 2007, 497; Gringer 2010, 224) ile irtibata geçerek bu adamın güvenini kazanıp kendisine yardım etmeye hazır hale getirmiştir -ya da öyle sanmıştır!-. Bolis'e IV. Ptolemaios için, Akhaios'u kurtaracak bir plan bulmaktan öte kabul edilir başka bir hizmetinin olamayacağını söylemiştir. Ayrıca Bolis'e bu işte dilediği gibi kullanmak üzere 10 talanta avans vermiştir.



Fig. 2. Sardeis Surları

Bolis ise bu durumu kendisi için iyi bir firsat olarak görmüş bir yandan IV. Ptolemaios'tan intikamını alırken -nedeni belli değildir- kesesini doldurmak bir yandan da III. Antiokhos'un gözüne girmek için hassas bir plan hazırlamıștır. Öncelikle işe, bir babanın oğluna olduğu gibi Akhaios'a sadakati ve bağlılı̆̆ ile bilinen Rhodos'taki Nikomakhos'a ve Ephesos'taki Melankomas'a şifreli mesajlar içeren bir dizi raporlar hazırlamıştır. Ardından III. Antiokhos'un savaş kampından ayrılarak önce Rhodos'a ardından da Ephesos'a gitmiş ve Nikomakhos ve Melankomas ile görüşerek onların güvenini kazanmıştır. Zira Bolis’in yelken açarak iletişime geçtiği bu kişiler daha önce Akhaios'un IV. Ptolemaios ile görüşmelerinde (bu durum söz 
konusu savaş başlamadan Akhaios'un bir şekilde IV. Ptolemaios ile iletişime geçtiğini kanıtlamaktadır: Grainger 2010, 223-24; Alten 2015, 63; 72) Akhaios adına elçilik yapmışlardı.

Bolis Ephesos'a geldiğinde sadık adamlarından biri olan Arianos'u, III. Antiokhos'un Girit birlikleri komutanı ve Sardis Kalesi arkasında yer alan ileri karakollardan birinde görev yapan arkadaşı ve hemşehrisi Kambylos'a göndermiş ve onunla en kısa zaman içinde görüşmek istediğini bildirmiştir (Poly VIII. 15. 3-5). Ancak o sıralar Sardis akropolisinde Akhaios'u kuşatmakla meşgul olan Kambylos, Arianos'u geri çevirmiştir. Bunun üzerine Bolis Giritli olması (Antikçağda Giritliler kurnazlıklarıyla ünlüydüler) nedeniyle yeni bir plan düşünmüştür. Bu sefer Arianus'u, görevi hakkında detaylı bilgiler içeren mektupla birlikle Kambylos'a göndererek onu kendi tarafına çekmeye çalışmıştır (Polyb. VIII. 17. 6-8). Bolis'in Sosibilos'un kendisine avans olarak verdiği 10 talanta'yı Kambylos ile aralarında eşit pay edeceğini bildirmesi üzerine Kambylos Bolis'le görüşmeyi ve bu işte onunla ortak haraket etmeyi kabul etmiştir. İki Giritli buluşup durumu kendi aralarında tahlil ettiklerinde kendileri açısından en karlı ve güvenli işin bu komplodan III. Antiokhos'u haberdar etmek olduğuna karar vermişlerdir. Böylelikle bir yandan Seleukos kralının güvenini kazanırken diğer yandan Akhaios'u da III. Antiokhos'a teslim ederlerse hem halihazırdaki 10 talanta kendilerinde kalacak hem de kral tarafindan cömertçe ödüllendirileceklerdi. Bunun üzerine Kambylos durumu III. Antiokhos’a açıklamış ve Akhaios'u hiçbir asker kaybetmeden kısa süre içinde kendisine teslim edeceğine dair garanti ve söz vermiştir. Antiokhos ise Akhaios için yapılan planın kendi işine yaraması teklifine şaşırarak kabul etmiştir. Kralın bu plana onay vermesiyle birlikte Bolis bu gelişmelerden hiçbir şekilde haberdar olmayan adamı Arianos'u Nikomakhos ve Melankomas'a göndererek onlardan gelecek şifreli bir mektubu Akhaios’a iletmeye söz vermiştir. Akhaios'un dostları ve elçileri olan Melankomas ve Nikomakhos'ta birinin eline geçmesi durumunda kimsenin anlayamayacağı şekilde tasarladıkları mektubu Arianos'a teslim etmişlerdir. Bu şekilde Melankomas ve Nikomakhos tarafından kendisine verilen mektubu Arianos gizlice kuşatmayı yararak Kambylos'un görmezden gelmesiyle- Akhaios'a iletmeyi başarmıştır. Arianos, Akhaios'a en başından itibaren planın nasıl olacağını anlatarak Sosibios-Bolis, Melankomas-Nikomakhos, Kambylos hakkında herşeyi detaylı bir şekilde açıklamıştır. Arianos; Kambylos ve Bolis arasındaki anlaşmayı bilmediği ve olayların gerçek yüzünü bilmediği için bütün iyi niyetiyle Akhaios'u ikna etmeye çalışmıştır. Akhaios ise Arianos'un sorgulaması ile Melankomas ve Nikomakhos'un şifreli harfler içeren mektuplarına güvenip cevap vermiş ve Arianos ile cevabı göndermiştir. Cevapta kaderini Nikomakhos'un eline bıraktığını ve güvenliğini onlara teslim ettiğini bildirmiştir. Ancak bu cevap hiçbir şekilde Nikomakhos'un eline geçmemiştir. Mektubu okuyan Bolis ile Kambylos, Arianos'a Nikomakhos’tan geldiğini bildirdikleri bir mektup vererek Akhaios'un kurtuluş için kendilerine güvenmesini salık veren bir mektup teslim etmişlerdir. Mektupta aysız gecede Arianos ile birlikte Bolis'in gizlice akropo lis'e girip Akhaios'la birlikte kaçması planlanmıştı. Bu sırada Akhaios'un kıyafet olarak kral gibi değil, eski püskü ve sıradan şeyler giyerek tanınmamasına gayret edilecekti. Böylelikle Akhaios, III. Antiokhos Sardis'i kuşatırken kendisi IV. Ptolemaios'un da desteğiyle Koile Suriyesi'ne gidip Antiokheia'da törenle karşılanacak ve Seleukos kralına karşı savaşına kaldığı yerden devam edecekti.

Ancak Bolis ve Kambylos'un esas planı başkaydı. Onlara göre Akhaios akropolis’ten aşağ yalnız başına ya da Bolis ve Arianos ile birlikte gelirse daha kolay tuzağa düşerdi. Ama başkaları tarafından Akhaios'a eşlik edilirse onun canlı yakalayıp Antiokhos'u memnun etmek zor olacaktı. Arianos kaleden çıkması için Akhaios'a yolu gösterecekti. Bolis ise onu alıp Kambylos'un pusuda beklediği yere götürecekti. Detaylı bir şekilde planlanan kaç güzergahında

Akhaios'a ne ağaçlıklı şehir yolundan geçerken gecenin karanlığından yararlanarak kaçma ne de çaresizlik içinde kendisini uçurumdan atarak kurtulma şansı tanınmıştı. Kaçırma operas- 
yonunun organize edildiği gece Bolis gizlice III. Antiokhos'un kampına vardı. Kambylos, Bolis'i Antiokhos'un yanına götürerek kralla takdim etti. Kral onları nezaketle karşılayarak her ikisini cesaretlendirdi ve onlara ödüllerinin sözünü verdi.

$\mathrm{Bu}$ şekilde planlarını uygulamak üzere kamptan ayrılan Bolis kısa süre sonra hiçbir şeyden haberi olmayan Arianos ile kampın dışında buluşarak birlikte şafaktan önce gizlice akroplisi çevreleyen yukarı kaleye girdiler. Plan Akhaios'un yalnız başına değilde güvendiği birkaç kişiyle birlikte çıkmasının haricinde sorunsuz işlemiş görünür. Bolis ve Arianos, Akhaios’u alarak aysız gecede kaleden çıkarıp sarp yerlerden indirdiği sırada Kambylos ve adamları pusudan çıkmıştır. Bolis de Akhaios'u kendi tarafına çekince Kambylos Akhaios'un yanındakilere saldırmıştır. Bolis ise bu sırada Akhaios'un canlı ele geçmesi için onu pelerininin altına alarak korumuştur. Akhaios ihanete uğradığını, ancak elleri arkada bağlanınca anlamıştır (Polyb. VIII. 20. 6-7; Alten 2015, 56-57).



Fig. 3. Antiokhos III Megas sikkesi

Kambylos ve adamları kralın yanına gelerek kralın amcası Akhaios'u elleri ve ayakları bağlı olarak yere atmıştır. Dramatik tarih anlatısına bir örnek teşkil edercesine Polybios (VIII. 20. 911) III. Antiokhos'un bu sırada şaşırarak uzun süre konuşmadan onu izlediğini ve ceza olarak vereceği cezayı uygularken ne kadar zorlanacağını ve tüm beklentilerin aksine bu eylemlerin kadere bağlı şeyler olduğunu düşünerek gözyaşlarına boğulduğunu ifade etmiştir. Kendi birlikleri ve düşman kuvvetleri tarafından Sardis'in akropolis'inde olduğu düşünülen Akhaios, elleri ve kolları bağlı bir şekilde III. Antiokhos'un esiri olmuştur. Kralın çadırına doluşan askerler gelenek olduğu üzere kendi gözleriyle olanları görmek için çadıra gitmişlerdir. Konsey toplantısı yapılarak Akhaios'un cezası hakkında teklifler sunulmuştur.

Polybios’a (VIII. 21. 2-3) göre, Akhaios'un ilk olarak kolları ve bacakları kesilmiş, ardından kafası kesilerek eşek derisine sarılan vücudu kazığa oturtulmuştur (ayrıca bk. van Proosdij 1934, 347-350; Bugh 2006, 147). Tüm olanlar orduya anlatılmış; herkes coşku ve sevinç içerisinde nidalar atmıştır. Bu sırada Akhaios'un eşi Laodike, Akhaios'un kamptan ayrıldığını bilen tek kişiydi. Karargâhtaki kargaşa ve karışıklığa tanık olunca gerçek ona gaipten haber verilmişti. Haberci ulaştı̆̆ında ona Akhaios'un kaderini bildirerek karşı taraf ile anlaşma yapmak için barış istemesini teklif etmiştir. İlk olarak kalede herhangi bir hareket olmasa da daha sonra ağıt sesleri yükselmiştir. Çünkü olay, tuhaf ve tamamen umulmadıktı. Karargâhta daha fazla kargaşa çıkmış ve anlaşmazlıklar baş göstermiştir. III. Antiokhos da akropolis kuşatmasında baskıyı artırmış ve surlar önünde çetin çarpışmalar başgöstermiştir. Ancak lidersiz kalan savunma hattında gedik açılmış ve iç kale düşmüştür. Bu sırada Akhaios'un kaledeki birlikleri ölümünden sonra Akhaios'un eşi Laodike taraftarları ve Aribazos yönetimindeki birlikler olmak üzere teslim olma ya da direnme adına ikiye bölünmüştür: Her iki grup da kale ele geçirilince bir süreliğine direnmiş de olsalar III. Antiokhos'un ordusunu püskürtememiş ve herkes kendi canının derdine düşerek teslim olmak zorunda kalmışlardır (Ehling 2007, 498; Grainger 2010, 224). 


\section{Sonuç}

Yaklaşık iki yıl süren kuşama ardından hile ve ihanetle ele geçirilen kent III. Antiokhos'un ordusu tarafından yağmalanmıştır. Ancak kentin tarihsel, stratejik ve ekonomik öneminden ötürü III. Antiokhos kenti yeniden canlandırmak amacıyla eşi Laodike onuruna düzenlenen festival onuruna vergiden muafiyet (= ateleia [ả $\left.\varepsilon_{\varepsilon} \lambda \varepsilon ı \alpha\right]$ ) sağlamış ve tarımsal faaliyetlerin artması için kente yardımcı olmaya çalışmıştır. Kente yaptı̆̆ 1 hayırhahlık için geride kalan az sayıdaki Sardis halkı III. Antiokhos ve eşi Laodike için sevgi gösterinde bulunmuştur. Kral ve eşi birkaç ay bu kentte kalmış ve Sardis’ten, özellikle yeniden ele geçirdiği diğer topluluklardan elçiler kabul etmiştir (Ma 1999, 62).

III. Antiokhos MÖ 213/212 kışında Suriye’ye doğru yola çıkmadan önce Küçük Asya'nın Torosların batısında kalan topraklarının valisi olarak Zeuksis'i bırakmıştır. Sardislilere yazdığı mektupta kentin yeniden yapılanması için kereste sağlanması ve Zeuksis'in uygun gördüğü gibi taşınması hususuyla valinin ilgilenmesini belirten mektuplar kaleme almıştır (SEG XXXIX. 1283; 1; Ma 1999, 284-5 no. 1 str. 7-8). Akhaios İsyanı sırasında kuşatılan ve kısmen tahrip olan kentin onarılması, yapılan bu düzenlemelerle, kent eski görkemine kavuşturularak kentin Seleukoslara karşı olan bağlılığı yeniden sağlanmaya çalışılmıştır. III. Antiokhos bundan sonra rotasını doğuya çevirerek Partia, Armenia ve Baktria bölgelerine 7 y1l boyunca anabasis gerçekleştirerek megas unvanını haketme ve Seleukos Krallığı'nı en geniş sınırlara ulaştırma çabasına girişmiştir.

\section{Yazar Notu:}

Bu makale, “III. Antiokhos'un Hellenistik Krallıklar ve Roma ile olan İlişkileri” başlıklı yüksek lisans tezimin bir bölümünün genişletilmiş ve gözden geçirilmiş halidir. 2017 yılında "Archaeology and History of Lydia from the Early Lydian Period to late Antiquity ( $8^{\text {th }}$ century B.C. $-6^{\text {th }}$ century A.D.): An International Symposium” başl1klı sempozyumda özet bildiri olarak sunulmuş ve özet kitapçı̆̆ı yayınlanmıştır. 


\section{KAYNAKÇA}

Alten E. (2015) III. Antiokhos'un Hellenistik Krallıklar ve Roma ile olan Illişkileri. Yayınlanmamış Yüksek Lisans Tezi. Akdeniz Üniversitesi, Antalya 2015.

Arslan M. (2000) Antikçağ Anadolusu'nun Savaşçı Kavmi Galatlar. İstanbul 2000.

Arslan M. (2010) İstanbul'un Antikçağ Tarihi: Klasik ve Hellenistik Dönemler. İstanbul 2010.

Austin M. M. (1981) The Hellenistic World from Alexander to the Roman Conquest: A Selection of Ancient Sources in Translation. Cambridge 1981.

Bell K. S. (2007) Seleucid Frontier Policy in the East: The Nature and extent of imperial control. London 2007.

Bugh G. R. (2006) The Cambridge Campanion to the Hellenistic World. Cambridge 2006.

Cardinali G. (1968) Il Regno di Pergamo: Ricerchi di storia e di diritto pubblico. Roma 1906.

Ehling K. (2007) Der Tod des Usurpators Achaios”. Historia: Zeitschrift für Alte Geschichte 56/4 (2007) 497-501.

Gauthier Ph. (1989) Nouvelles inscriptions de Sardes II (Archaeological Exploration of Sardis/École Pratique des Hautes Études, IVe section. Hautes Études du Monde Gréco-Romain 15) Paris and Genova 1989.

Grainger J. D. (2010) The Syrian Wars. USA 2010.

Leake W. M. (1824). Journal of a Tour in Asia Minor, with Comparative Remarks on the Ancient and Modern Geography of that Country. London 1824. .

Leuze O. (1923) “Die Feldzüge Antiochos' des Grossen Nach Kleinasien und Trakien”. Hermes 58. 2 (Apr. 1923), 187-229.

Ma J. (1999) Antiochus III and the Cities of the Western Asia Minor. Oxford 1999.

Magie D. (1950) Roman Rule in Küçük Asya to the End of the Third Century after Christ. Princeton, vol I-II $1950 .$.

Malay H (1987) "Letter of Antiochus III to Zeuxis with Two Covering Letters (209 B.C.)”. EA 10 (1987) $7-17$

Mcdonald G. (2003) “Early Selucid Portraits”. JHS 23 (1903), 92-116.

Meadows A. (2009) "The Eras of Pamphylia and the Seleucid Invasions of Asia Minor". The American Journal of Numismatic 21 (2009) 51-88.

Mitchell S. (1993) Anatolia: Land, Men, and Gods in Asia Minor. Vol. I:The Celts and The Impact of Roman Rule. Oxford 1993.

Mørkholm O. (1969) "Some Seleucid Coins of the Mint of Sardes". Nordisk Numismatisk Arsskrift (1969), 5-20.

Newell E. T. (1977) The Coinage of the Western Seleucid Mints from Seleucus I to Antiochus III. ( Numismatic Studies IV). The American Numismatic Society. Newyork 1977.

Piejko F. (1987) The Settlement of Sardis after the Fall of Achaeus”. AJPh 108. 4 (1987) 707-28.

Sartre M. (2003) L'Anatolie héllenistique: de l'Égée au Caucase (334-31 av. J.-C.). Paris 2003.

SC I Seleucids Coins, A Comprehensive Catalogue. Part I. vol. I. American Numismatic Society. Ed. A. Houghton - C. Lorber. Lancaster/London. 2002.

Schmitt H. (1964) Untersuchungen zur Geschichte Antiochos' des Grossen und seiner Zeit (Historia Einzelschrift 6). Stuttgart 1964.

SEG Supplementum Epigraphicum Graecorum. Brill 1923-

Taylor M. (2013) Antiochus the Great. Great Britain 2013.

Tcherikover V. (1959) Hellenistic Civilization and the Jews. Philadelphia 1959.

van Proosdij B. A. (1934). “De Morte Achaei”. Hermes 69 (1934), 347-50. 
